\title{
CASE REPORT: THE USE OF UNIVERSAL HIGHLY AESTHETIC NANO-HYBRID COMPOSITE FOR RESTORATION OF PRIMARY MOLARS
}

\author{
Milena Georgieva-Dimitrova
}

\author{
Department of Pediatric Dentistry, Faculty of Dental Medicine, \\ Medical University of Varna
}

\begin{abstract}
INTRODUCTION: The most interesting aspect of dental practice can be pediatric dentistry. Primary posterior molars can be restored with aesthetic resin-based composite materials. Restorative dentistry offers different choices for practitioners. The most important factor for choosing resin-based composite for children is a satisfactory cooperative behavior.

AIM: The aim of this article is to show the opportunity for restoration of primary molars with universal high aesthetic nano-hybrid composite.

MATERIALS AND METHODS: The child's level of cooperation was assessed before the treatment using the Frankel scale. In this study a universal nano-hybrid composite (Omnichroma) was used for restoration of mandibular primary molar - 75 .

RESULTS: A 4-year-old girl came to the dental office. After the intraoral examination an occlusal carious lesion on the left mandibular primary molar was established. The child was cooperative and allowed local anaesthesia followed by rubber dam isolation. A minimally invasive preparation of the cavity was performed. The tooth was restored with a highly aesthetic universal nano-hybrid composite Omnichroma layer by layer.

CONCLUSION: Resin composites are a method of treatment for primary dentition. The contemporary generation of composites, such as universal composite Omnichroma provide, excellent aesthetic result as filling material as well as long-term wear resistance.
\end{abstract}

Keywords: resin composite, primary molar, restoration materials

Address for correspondence:
Milena Georgieva-Dimitrova
Faculty of Dental Medicine
Medical University of Varna
84 Tzar Osvoboditel Blvd
9000 Varna
e-mail: dr.milena.georgieva89@gmail.com

Received: October 23, 2019

Accepted: November 17, 2019

\section{INTRODUCTION}

Many choices are available to the practitioner of restorative dentistry for children (1). The rubberdam is the best option to create an ideal operative field and to achieve a good isolation. This condition is really important for the use of adhesive materials that are moisture sensitive. Resin composite materials can be used to restore primary molars that are fractured, malformed or with a caries lesion (2). 
General anesthesia allows the treatment of patients with special health care needs and small children with Early Childhood Caries and non-cooperative behavior. This is a method of pharmacological behavior management that provides optimal treatment conditions $(3,4)$.

In the group of 0 to 5 -year-old children the most common filling material for restoration is glass-ionomer cement (GIC) for children treated under general anesthesia as well as those treated in the dental office. In this age group composite restorations are not as useful as in children with mixed and permanent dentition. The better strength and aesthetics of composite materials make them the best material of choice for permanent teeth in the group of 12- to 18-yearolds (3).

The major difference between the treatment of children and adults is the management of the behavior. Understanding of the normal abilities of the children at different ages, especially the preschool group, is necessary to diagnose and successfully manage the behavior $(5,6)$.

Resin-based composite materials are effective for class I, II and V in primary dentition. Good cooperation of the child is necessary for the application of these filling materials, because they have strict application protocol and require extra time to restore primary posterior teeth (2).

The role of the parents during a dental appointment is extremely important for the cooperative behavior of the children in preschool age. The special skills of the pediatric dentists are premise for pleasant work with this age group and determine the relationship with the child (5).

High risk of caries, uncooperative behavior of the child and impossible tooth isolation are contraindications for application of adhesive dental materials - pit and fissure sealants, resin-based composites, compomers, and GICs including resin-modified ones (2).

\section{AIM}

The aim of this article is to show the opportunity for restoration of primary molars with universal highly aesthetic nano-hybrid composite.

\section{MATERIALS AND METHODS}

The child's level of cooperation was assessed before the treatment using the Frankel scale. In this study a universal nano-hybrid composite (Omnichroma) was used for restoration of mandibular primary molar - 75 after rubber dam isolation.

\section{RESULT}

A 4-year-old girl came to the dental office for a prophylactic visitation. Cooperative assessment was done before the treatment using the Frankel scale. According to this scale there are 4 different types of behavior - definitely negative, negative, positive and definitely positive.

Rating 4: Definitely Positive - good rapport with the dentist, interest in the dental procedures, laughter and enjoyment.

The child fulfilled the criteria for definitely positive behavior - good rapport with the dentist, interest in the dental procedures, laughter and enjoyment.

After the intraoral examination an occlusal carious lesion on the left mandibular primary molar was established. The carious lesion was cavitated in the central pit with demineralized outlines (Fig. 1). The child had no complaints of pain. The child was cooperative and allowed local anaesthesia followed by good rubber dam isolation.

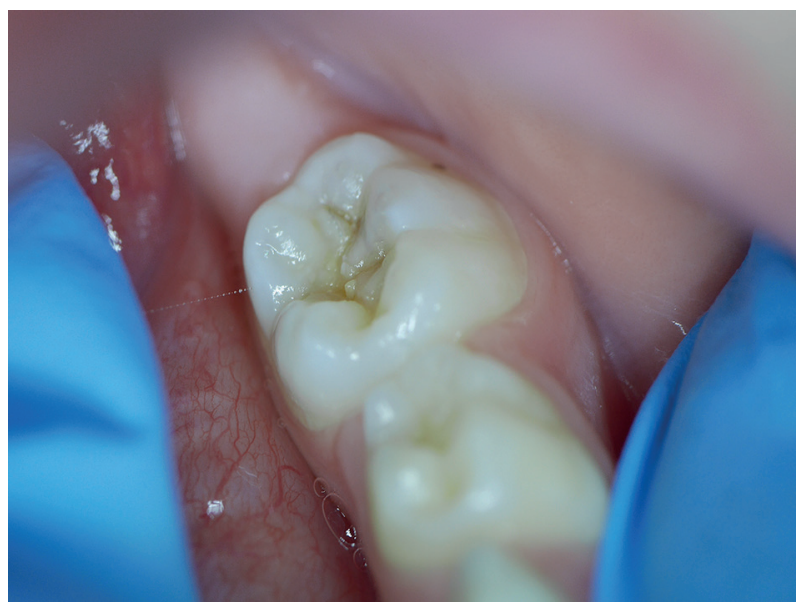

Fig. 1. Caries lesion on tooth 75

A minimally invasive preparation of the cavity was performed, removing only the irreversible infected outer half of the dentin and undermined enamel. It was impossible to make two separate cavi- 
ties due to lack of hard tooth tissues between the lesions located on the distal and central pit (Fig. 2).

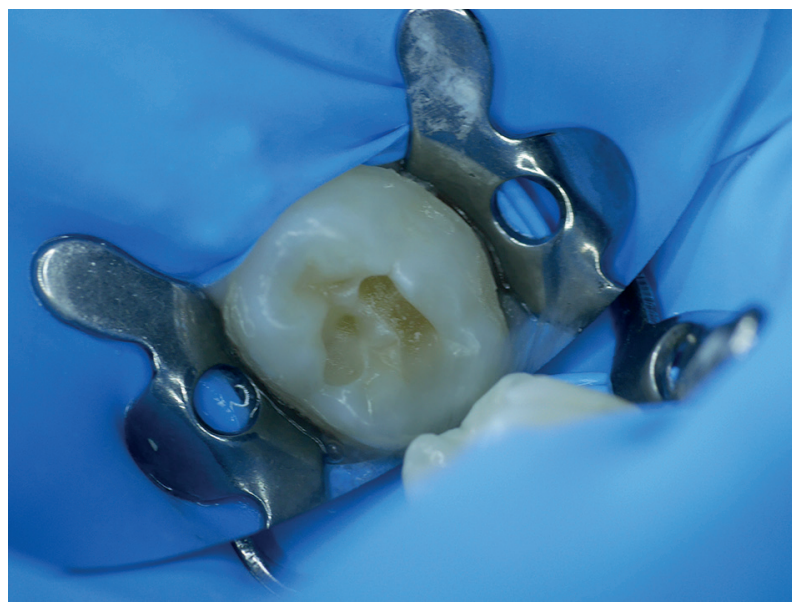

Fig. 2. Cavity preparation

After the cavity preparation, the enamel was treated with Tokuyama etching gel HV for $15 \mathrm{sec}-$ onds (Fig. 3).

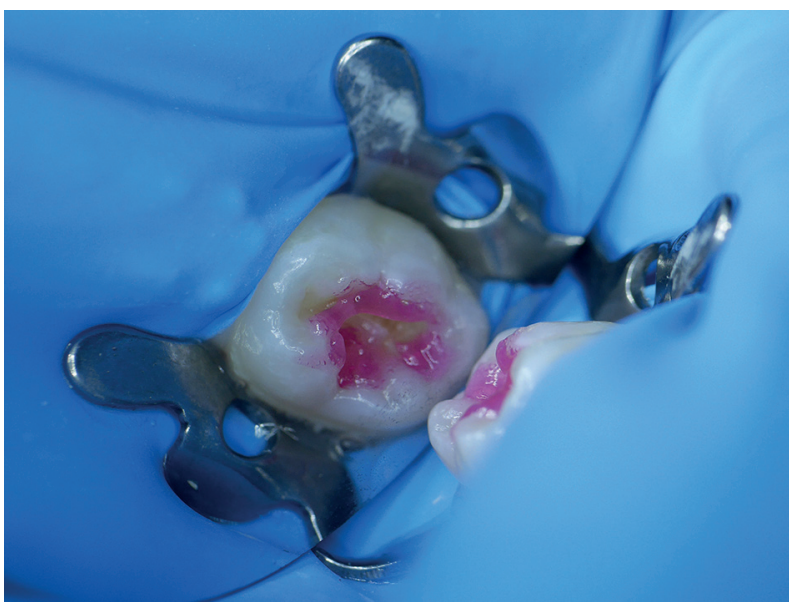

Fig. 3. Enamel treatment

A $7^{\text {th }}$ generation one-bottle one-step bonding agent - Tokuyama bond force II with fluoride releasing potential was applied. The procedure for use was short: a suitable amount of bonding agent was applied with the brush, the walls of the cavity were brushed to properly wet them, a 10 -second pause followed, mild air was applied for approximately $5 \mathrm{sec}-$ onds, and the material was light cured for 10 seconds. The tooth was restored with a highly aesthetic universal nano-hybrid composite Omnichroma layer by layer. It was light- cured for 20 seconds (Fig. 4). A highly aesthetic result was achieved on tooth 75 (Fig. 5).

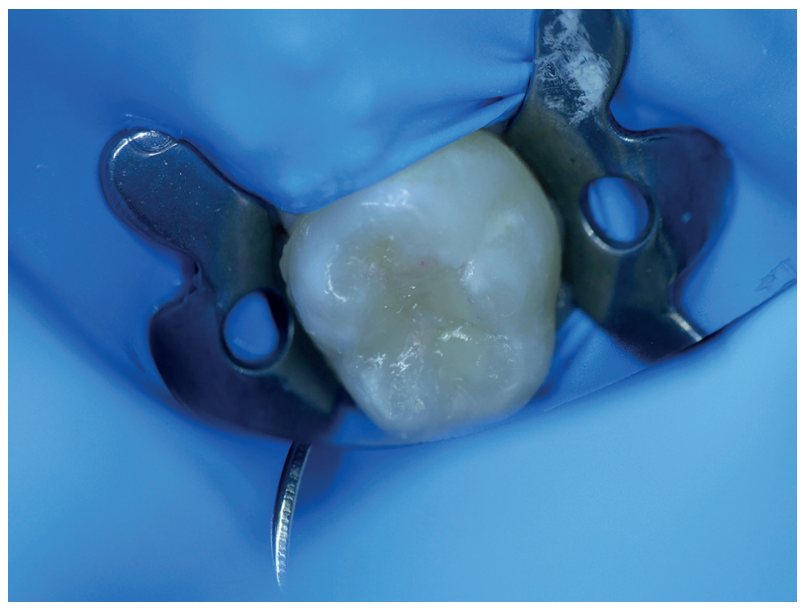

Fig. 4. Final restoration before isolation removal

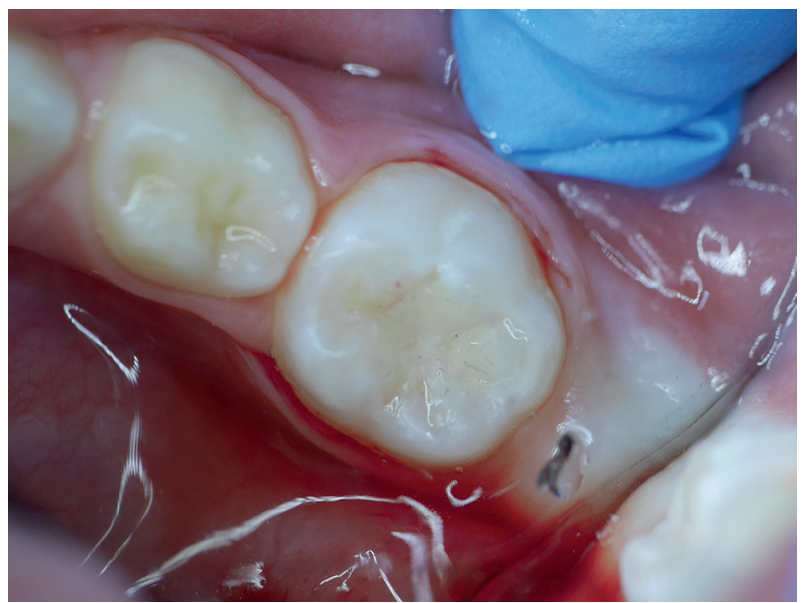

Fig. 5. Final aesthetic restoration on primary molar

\section{DISCUSSION}

A study in 2018 about the overall performance of two kinds of materials - resin-modified glass ionomer cement and composite resin was made. The survey included healthy cooperative children aged $4-7.5$ years. The successful rate of these two materials showed no significant difference in restoring class II caries lesions on primary molars and both of them can be used. After two years of follow-up occlusal wear of glass ionomer restorations was registered, but it had no clinical importance (7).

A study was conducted including children at an average age of $6.79 \pm 1.81$ years with occlusal caries in the outer half of dentin. They were separated 
into two groups - the first test group was treated with caries sealant with flowable resin. The second control group was treated with partial caries excavation followed by restoration. Before the treatment the Facial image scale was used to determine the children's anxiety. The results of this study showed no difference between the two methods of treatment and there was no progression of the caries process in both groups after a 2-year follow-up (8).

In 2018, a study about retention, color matching, marginal discoloration and adaptation, presence of secondary caries, anatomic form and postoperative sensitivity after application of bulk fill composite and conventional composite was conducted. Object of the examination were 80 patients with occlusal caries on primary molars and 160 restorations were made. The short-term data from a 1-year follow-up showed that both materials had great success. There was a difference between the postoperative sensitivity in cases completed with bulk fill restorative material (9).

It took decades before any changes were introduced in pediatric restorative dentistry and restorative techniques for primary dentition. Adhesive restorative materials and bonding systems, such as GICs and resin-based composites, have been developed for restorations in primary dentition. This allowed more conservative preparation of the hard tooth tissues and when the materials are applied properly they provide aesthetics and mechanical durability until the physiological exfoliation of the primary teeth close to amalgam and stainless steel crowns. This is a dynamic combination of ever-improving materials and tried-and-true techniques (10).

Children with a high risk of caries and negative behavior that do not allow proper tooth isolation to prevent contamination are not recommended for composite restorations. Composite placement also depends on polymerization shrinkage and the extent of the tooth decay. They are helpful in pediatric restorative dentistry for primary and permanent dentition. They can be used for preventive restorations combined with sealants, severely destroyed teeth and esthetic build-ups such as strip crowns (11).

\section{CONCLUSION}

Resin composites are a method of treatment for primary dentition. The contemporary generation of composites, such as universal composite Omnichroma provide, excellent aesthetic result as filling material as well as long-term wear resistance. This material is easy to handle, with reduced chair time, and useful in the daily practice. Resin composite restorations are indicated for cooperative patients who allow rubber dam isolation. Caries risk assessment of the child is an important step in treatment plan decisions.

\section{REFERENCES}

1. Berg JH. The continuum of restorative materials in pediatric dentistry--a review for the clinician. Pediatr Dent. 1998;20(2):93-100.

2. Soxman JA. The handbook of clinical techniques in pediatric dentistry. 1st ed. Wiley-Blackwell; 2015

3. Andreeva R. Assessment of different types of materials of children treated under general anesthesia. Med Inform. 2018; 2:432-8.

4. Tate AR, Ng MW, Needleman HL, Acs G. Failure rates of restorative procedures following dental rehabilitation under general anesthesia. Pediatr Dent 2002;24:69-71

5. Croll TP. Restorative dentistry for preschool children. Dent Clin North Am. 1995;39(4):737-70.

6. Srivastava VK. Modern Pediatric Dentistry. 1st ed. Jaypee Brothers Medical Publishers (P) Ltd.; 2011.

7. Dermata A, Papageorgiou SN, Fragkou S, Kotsanos N. Comparison of resin modified glass ionomer cement and composite resin in class II primary molar restorations: a 2-year parallel randomised clinical trial. Eur Arch Paediatr Dent. 2018;19(6):393-401. doi: 10.1007/s40368-018-0371-7.

8. Dias KR, de Andrade CB, Wait TT, Chamon R, Ammari MM, Soviero VM, et. al. A. Efficacy of sealing occlusal caries with a flowable composite in primary molars: A 2-year randomized controlled clinical trial. J Dent. 2018; 74:49-55. doi: 10.1016/j. jdent.2018.05.014.

9. Oter B, Deniz K, Cehreli SB. Preliminary data on clinical performance of bulk-fill restorations in primary molars. Niger J Clin Pract. 2018;21(11):1484-91. doi: 10.4103/njcp.njcp_151_18.

10. Nowak AJ, Mabry TR, Christensen JR, Townsend JA, Wells MH. Pediatric Dentistry Infancy Through Adolescence. 6th ed. Elsevier Inc.; 2019.

11. Donly KJ, García-Godoy F. The Use of Resin-based Composite in Children: An Update. Pediatr Dent. 2015;37(2):136-43. 